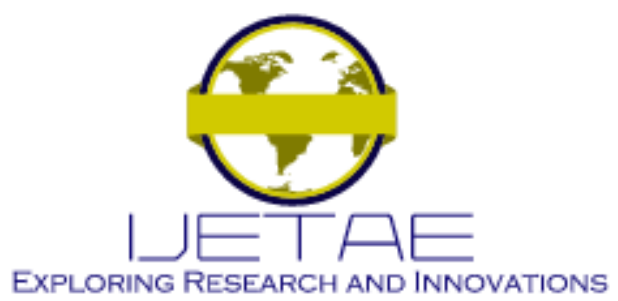

International Journal of Emerging Technology and Advanced Engineering

Website: www.ijetae.com (E-ISSN 2250-2459, Scopus Indexed, ISO 9001:2008 Certified Journal, Volume 11, Issue 09, September 2021)

Manuscript Received: 02 August 2021, Received in Revised form: 10 September 2021, Accepted: 15 September 2021

DOI: 10.46338/ijetae0921_03

\title{
The Determining the Flight Routes of Unmanned Aerial Vehicles Groups Based on Improved Ant Colony Algorithms
}

\author{
Hennadii Khudov ${ }^{1}$, Oleksandr Oleksenko ${ }^{2}$, Vadym Lukianchuk ${ }^{3}$, Volodymyr Herasymenko ${ }^{4}$, \\ Yaroslav Yaroshenko ${ }^{5}$, Oleksiy Ishchenko ${ }^{6}$, Dmytro Ikaiev $^{7}$, Oleg Golovchenko ${ }^{8}$, Anatolii Volobuiev ${ }^{9}$, \\ Yevhen Drob $^{10}$, Yuriy Solomonenko ${ }^{11}$, Irina Khizhnyak ${ }^{12}$ \\ 1,2,3,10,11,12 Ivan Kozhedub Kharkiv National Air Force University, Ukraine, Kharkiv, 61023 \\ ${ }^{4,5,6,7,8}$ National Defense University of Ukraine named after Ivan Cherniakhovskyi, Ukraine, Kyiv, 01001 \\ ${ }^{9}$ Central Researching Institute of the UA Armed Forces, Ukraine, Kyiv, 03049
}

\begin{abstract}
It is proposed to use an improved ant colony algorithm to determine the flight paths of unmanned aerial vehicles groups to the objects of intrest. A study was conducted on the application of the MAX-MIN Ant System to simultaneously determine the flight paths of several groups of unmanned aerial vehicles from different airfields to different objects of interest. Obstacles in the path of the unmanned aerial vehicles flight are also taken into account. As an example, the problem of a unmanned aerial vehicles breakthrough of an air defense system is considered. The number of unmanned aerial vehicles required to destroy the object of impact with a given probability is taken into account. The efficiency of the algorithm in the conditions of non stationary environment is also investigated.
\end{abstract}

Keywords - unmanned aerial vehicle, group, ant colony algorithm, route, flight, optimization

\section{INTRODUCTION}

One of the most important areas in modern aviation is related to the development of unmanned aerial vehicles (UAVs). UAVs are used in various fields, such as agriculture [1], oil and gas industry [2-3], forestry [4], military industry (Armenia Azerbaijan conflict [5], Civil War in Syria [6-7]), security systems [8], medicine [9] and so on. Modern UAVs are a high-tech system with elements of artificial intelligence, integrated into the general system of information gathering and decision-making.

The most important issue in the use of UAVs is the choice of the flight route. When choosing a flight route, the UAV must solve its problem with the required quality and efficiency. On the other hand, the quality and efficiency of the problem being solved by the UAV largely depends on the correct choice of the UAV flight route.
At the same time, the process of selecting the optimal flight routes is particularly difficult. The choice of the optimal flight route depends on many factors. First of all, on the chosen criterion of the route optimality.

The definition of UAV flight routes is traditionally reduced to various kinds of optimization problems.

In the paper, for example, we will consider the problem of a UAV flight to an object of interest for the purpose of reconnaissance or destruction. Objects of interest will be understood as objects of impact. Let us pose the problem of determining the optimal flight route of the UAV to the target of impact. Such tasks were typical when using UAVs in the recent Karabakh conflict [5], [10].

\section{Literature REVIEW AND PROBLEM Statement}

Papers [11-12] propose the UAV's routes with maximum of the information in a region of interest in a fixed time. The main disadvantage of [11-12] is that the information decreases over time.

Paper [13] propose the UAV's route for the search of radio frequency source. Paper [14] propose the method [13] to cover the maximum area. Papers [15-16] overcome uncertainties in the environment for method [13]. The main disadvantages of [13-16] are the disregard of the impact on the UAV and the absence of forbidden zones.

In the papers [17-18] navigation algorithm is proposed to improve the all-terrain capabilities. The results [17-18] are used for unmanned ground vehicle only.

Papers [19-20] propose the method of linear programming for determent the collision-free route. The planning is realized by continuously adjusting the points defined between the start and goal points. The main disadvantage of [19-20] is the absence of forbidden zones. 


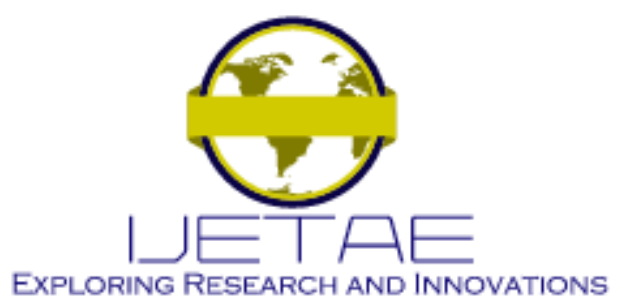

International Journal of Emerging Technology and Advanced Engineering

Website: www.ijetae.com (E-ISSN 2250-2459, Scopus Indexed, ISO 9001:2008 Certified Journal, Volume 11, Issue 09, September 2021)

Paper [21] proposes the genetic algorithms for route of UAV. Genetic algorithms [21], as noted in [22], are very cumbersome and require a significant computational resource.

Paper [23] propose the method of determent the path of UAV. The main constraint of 56 is "every target should be visited only once". The method [23] cannot be used to determine the route of the UAV in this case.

Paper [24] proposes the trajectory design for UAV without collision. The second-order agents are used in [24]. In the paper [25] results [24] are generalized for the UAV group. The main disadvantage [24-25] is the information values of the time-varying.

The paper [26] propose the route planning method. The aging of observation data is taken into account in [26]. The method [26] is successful in cases, where there are moving objects of interest. The method of route planning has been converted to a problem by creating an fitness function. The routes for online planning are on Fig. 1 [26].

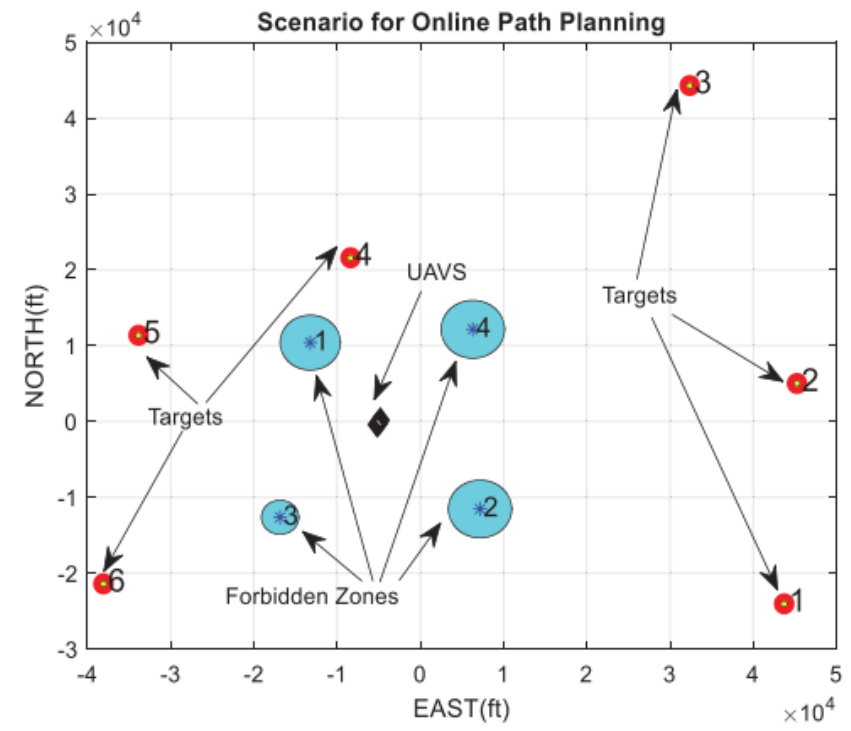

Fig.1. The routes for online planning are on Fig. 1 [26].

The semialgebraic models are used to define forbidden zones and desired region [27-28]. Also the algebraic primitives are used (1)-(2) [27-28]:

$$
F_{i}\left\{(x, y) \in \square^{2} \mid f_{i}(x, y) \leq 0\right\}, i=1, \ldots, M,
$$

where $F_{i}$ - forbidden zones (the blue regions on Fig. 1); $M$ - quantity of the forbidden zones;

$$
f_{i}(x, y)=\left(x-x_{i}\right)^{2}+\left(y-y_{i}\right)^{2}-r_{i}^{2},
$$

$r_{i}-$ the radius of the $\mathrm{i}$-th forbidden zone; $\left(x_{i}, y_{i}\right)-$ the center of coordinates of the i-th forbidden zone.

The forbidden region is defined as (3):

$$
F R=F_{1} \cup F_{2} \cup \ldots \cup F_{M}, F R \subseteq \square^{2} .
$$

The desired zones is defined as (4):

$$
D_{i}\left\{(x, y) \in \square^{2} \lg _{j}(x, y) \leq 0\right\}, i=1, \ldots, \mathrm{K},
$$

where $D_{i}$ - desired zones (the red regions on Fig. 1); $K-$ quantity of the desired zones;

$$
g_{j}(x, y)=\left(x-x_{j}\right)^{2}+\left(y-y_{j}\right)^{2}-r_{j}^{2}
$$

$r_{j}$ - the radius of the $\mathrm{j}$-th desired zone; $\left(x_{j}, y_{j}\right)-$ the center of coordinates of the $\mathrm{j}$-th desired zone.

The desired region is defined as (6):

$$
D R=D_{1} \cup D_{2} \cup \ldots \cup D_{K}, D R \subseteq \square^{2} .
$$

The main disadvantages [26] are its application only for theoretical calculations, idealization and simplicity of the construction of forbidden zones, applicability only for the two-dimensional case.

In [27] the creation of a method for determining the optimal flight route of the UAV, taking into account the presence of "no-fly zone" on the route. However, the possibility of changing the size of the "danger zones" is not taken into account, the route for the UAV group is not taken into account, and the route of the UAV group is determined taking into account the importance of the object of interest.

In [30-32] the swarm methods are used for images segmentation. Paper [30] proposes the artificial bee colony algorithm and ant colony optimization algorithm. Paper [31] proposes the methods for determining the contours of objects. Paper [32] propose the methods for determining the contours of objects on tonal aerospace images. The ant algorithms are used in [30-31]. The main advantages of swarm methods in total and ant colony algorithm are [3032]:

- the tendency to loop in local optimums;

- the multi-agency implementation; 


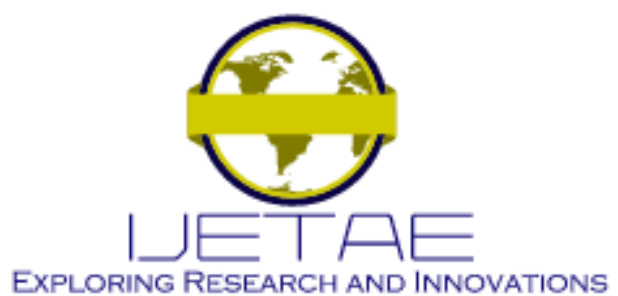

International Journal of Emerging Technology and Advanced Engineering

Website: www.ijetae.com (E-ISSN 2250-2459, Scopus Indexed, ISO 9001:2008 Certified Journal, Volume 11, Issue 09, September 2021)

- the search for a better solution is based on the decisions of all agents;

- the ability to adapt to changes in the environment;

- the ability to use to solve both discrete and continuous optimization problems.

The positive results obtained in previous studies [30 32] have prompted further research on the application of the ant algorithm to develop a number of methods for determining UAV flight options.

In the basic Ant System (AS), the probability of transition of the $k$-th agent to $i$-th turning point of the route (TPR), taking into account the availability of the route $L_{i}$ and the concentration of pheromones in this section $F_{i}$ at time $t$ is defined as (7) [31]:

$$
P_{i}^{k}(t)=\frac{F_{i}(t)^{\alpha} \cdot L_{i}^{\beta}}{\sum_{j=1}^{J} F_{j}(t)^{\alpha} \cdot L_{j}^{\beta}},
$$

where $\alpha \geq 0$ - weight of the pheromone and $\beta \geq 0-$ heuristic coefficients (accessibility of the site).

Parameter $L_{i}$ is determined taking into account "no-fly zone" (air defense systems, suppression zones of electronic warfare systems and other dangerous areas) (8) [32].

$$
L_{i}=\left\{\begin{array}{c}
1 / D_{i}, \text { if the } i \text {-th route passes outside } \\
\text { the "no-fly zone". } \\
\text { in other cases }
\end{array}\right.
$$

The basic AS solves large-scale optimization problems with accuracy at the level of other heuristic methods, such as genetic algorithm or waste simulation. But the basic AS is inefficient due to [33-34]:

- when applying the probabilistic rule of route selection, there is a probability of losing the best solution found;

- the low ascent near the optimum, due to approximately equal contribution of both better and worse solutions in the renewal of pheromones;
- preservation of obviously doomed options, which for large-scale tasks increases the number of calculations.

Therefore, for the improvement of the results they use the improved ant algorithms (ASE - basic Ant System with elite ants, ASR - rank Ant System, ACS - Ant Colony System, MMAS - MAX-MIN Ant System). It is more expedient to apply the MMAS, which in comparison with other varieties of AS finds the best solutions in the shortest time and has the best index of the average relative accuracy [32-33]. Its characteristic features are that [35-37]. There are:

- at each iteration, pheromones are added only to the TPR edges of the best route according to rule (9);

$$
F_{i}(t+1)=\left[(1-\rho) F_{i}(t)+\Delta F_{i}^{b e s t}\right]_{F_{\min }}^{F_{\max }},
$$

where $F_{\min }$ and $F_{\max }-$ maximum and minimum pheromone levels;

and $\Delta F_{i}^{\text {best }}$ is defined as (10):

$\Delta F_{i}^{\text {best }}=\left\{\begin{array}{ll}\frac{1}{L_{b e s t}}, \text { if the } i \text {-th route }- \text { the best in iteration } \\ 0\end{array}\right.$,

$L_{\text {best }}$

- the way of the best agent. This is the best route found in the current iteration, $L_{i b}$, or the best solution found since the algorithm started, $L_{b s}$;

- the number of pheromones on the route between turning points is limited in the range $\left[F_{\min }, F_{\max }\right]$;

- at the beginning of the algorithm, the amount of pheromone on each edge of the graph is taken equal to $F_{\max }$.

Example of UAV flight route presentation is in Fig. 2. 


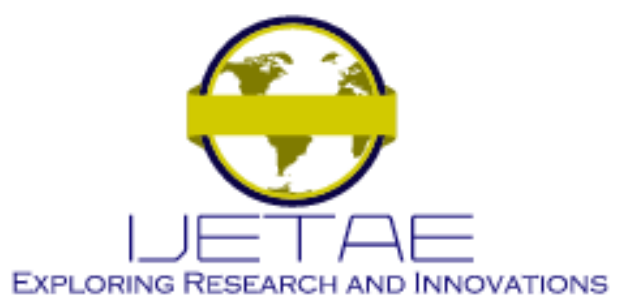

International Journal of Emerging Technology and Advanced Engineering

Website: www.ijetae.com (E-ISSN 2250-2459, Scopus Indexed, ISO 9001:2008 Certified Journal, Volume 11, Issue 09, September 2021)

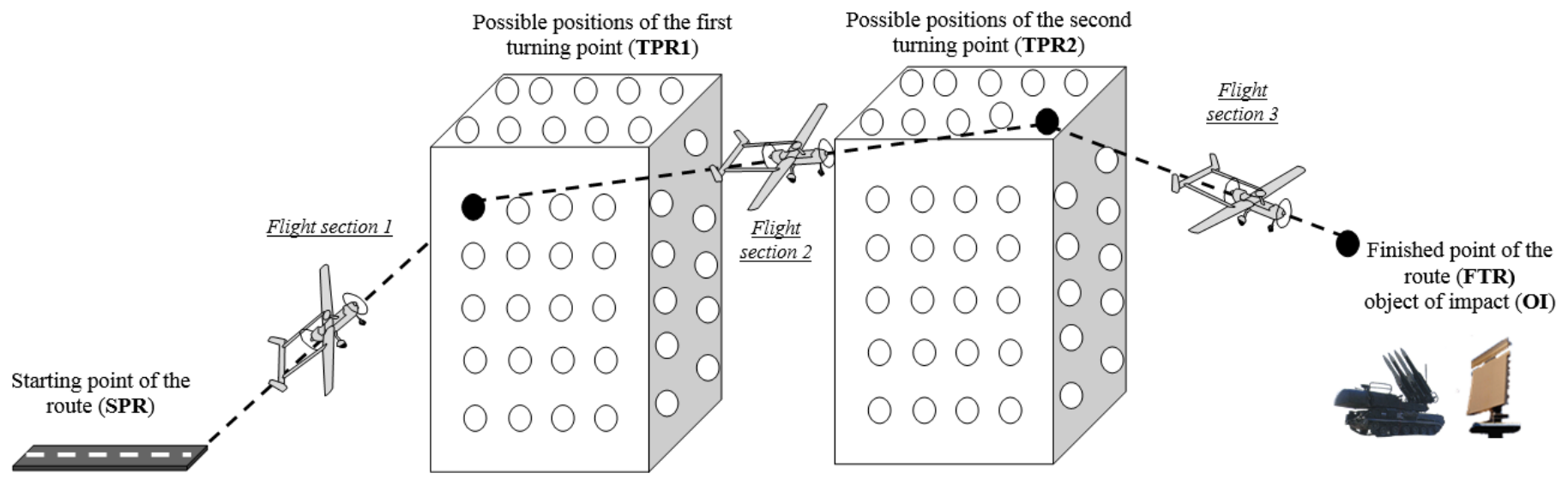

Fig. 2. Example of UAV flight route presentation

\section{MATERIALS AND RESEARCH METHODS}

When conducting the study, the following restrictions and assumptions were made.

1. The air defense system is overcome by all UAVs simultaneously (one UAV operates on one object) on the flight section 2 (distance from TPR1 to TPR 2). This means that the turning points of the route TPR 1 and TPR 2 for the whole group of UAVs are the same.

2. One UAV or a group of UAVs are assigned to one the objects of impact (OI).

3. There may be a limit on the number of UAVs based on one aerodrome; in the absence of such a restriction, obviously, the optimal take-off of all UAVs from the nearest to the entrance to the breakthrough zone of the air defense (AD) of the base aerodrome.

4. The criterion of optimality is the achievement of a minimum of the total range from the airfields of the UAV base to the respective OI, provided that the "no-fly zone" encountered on the routes are bypassed. The availability of the route segment was calculated by (8).

The initial data of the control example given in [34] were taken as a basis. The number of TPR 1 and TPR 2 is increased to 60 , the number of finished points of the route (FPR) is 5, the number of starting points of the route (SPR) (UAV bases) is 3. "No-fly zone" are marked in Fig. 3 circles. There are no restrictions on the number of UAVs based on one aerodrome. The location of SPR, FPR, TPR 1, TPR 2, "no-fly zone" is shown in Fig. 3.
Fig. 2 shows the results of calculating the flight routes of the UAV to the OI and the breakthrough of the AD for the three implementations of the MMAS (to make it more clear, the routes obtained in the three implementations are superimposed on one figure).

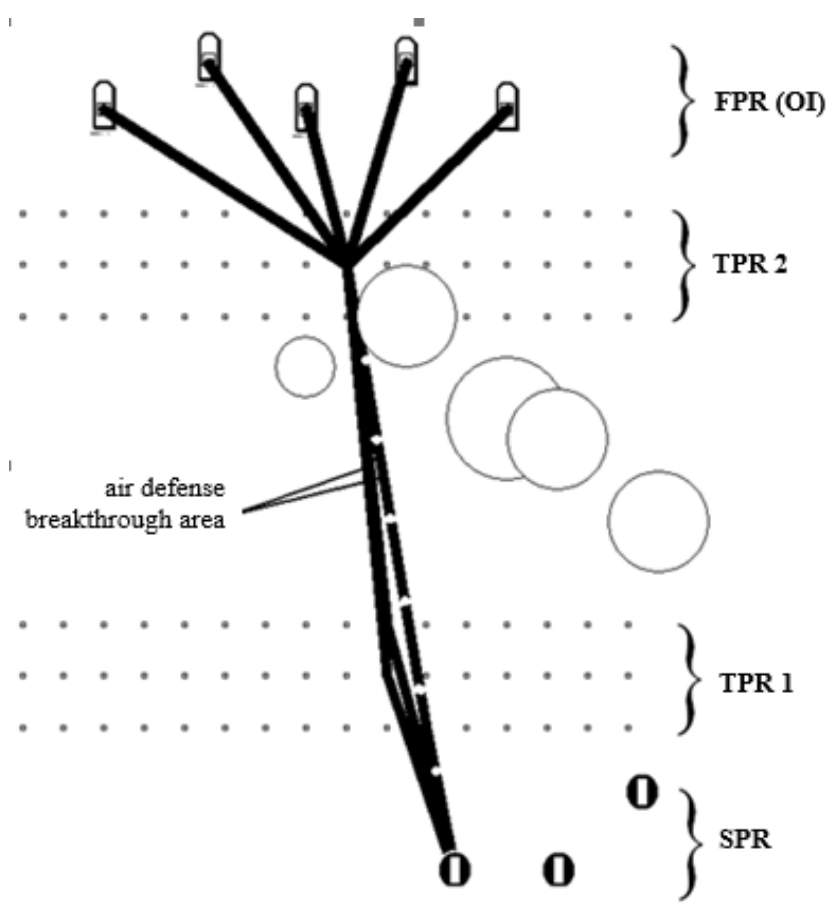

Fig. 3. The results of the application of MMAS to determine air defense breakthrough area 


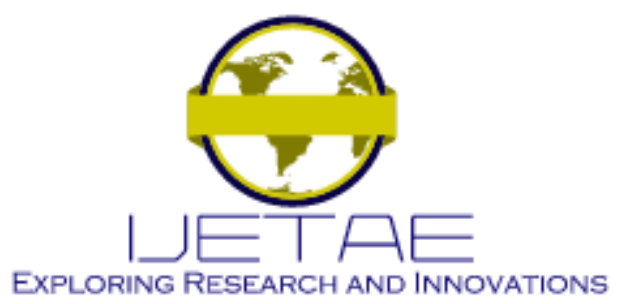

International Journal of Emerging Technology and Advanced Engineering

Website: www.ijetae.com (E-ISSN 2250-2459, Scopus Indexed, ISO 9001:2008 Certified Journal, Volume 11, Issue 09, September 2021)

It can be seen that in all three implementations the final sections of the route (sections of the exit to the OI) coincide. The first and second sections of the route in the two implementations are insignificantly different from the third, during which the optimal set of the routes was found by the selected criterion (shown in dotted lines).

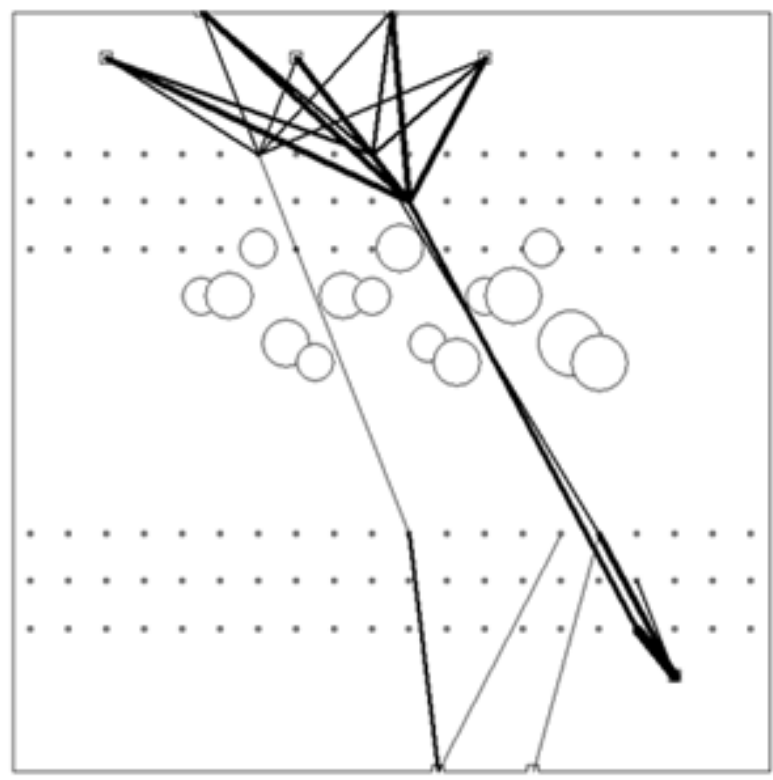

a)
It is also important to note that in all implementations for all routes, the algorithm, naturally, has chosen SPR as the nearest UAV base aerodrome, because there are no restrictions on the number of UAVs based at each aerodrome.

Fig. 4 shows the operation of the MMAS with increased to 15 the number of "no-fly zone". The algorithm again has quickly found the optimal solution.

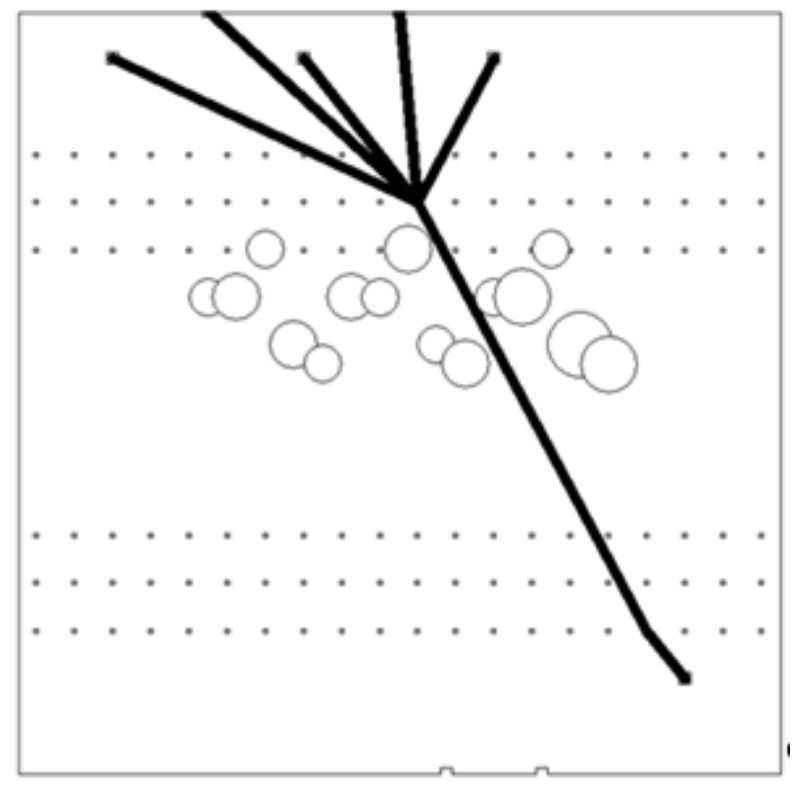

b)

Fig. 4. Consequence of MMAS work to determine the area of breakthrough of the air defense system, in the presence of fifteen "no-fly zone" (a - after 30; b - after 200 iterations)

The following experiment investigates the operation of the MMAS with changes in the location of "no-fly zone" (Fig. 5). Performance in a non-stationary environment is one of the advantages of ant algorithms [31-32], which contributes to the use of these algorithms in the study of processes occurring during hostilities.

Fig. 5 shows the progress of solving the problem, in which after the 60-th iteration of the algorithm changed two of the "no-fly zones" the corresponding circles are painted in the figure). The algorithm begins to build a new solution: after 85 iterations, this solution is not yet optimal, because the result is affected by the high level of pheromones in the third sections of the routes (areas of access to the object of impact), obtained in the first 60 iterations. However, after 150 iterations, the optimal solution appears, which begins to dominate after 290 iterations of the algorithm.
On other, suboptimal routes, the pheromone level gradually decreases due to evaporation.

The results of determining the range of the $\mathrm{AD}$ and UAV flight routes to the OI using MMAS do not take into account the impact of the importance of the objects of impact and the number of UAVs (outfits) required to destroy the object of impact with a given probability or degree of UAV damage.

Let's change the order of calculating the availability of the section of route $L_{i}$. In contrast to (2) in the following formula for calculating the cost of overcoming the section of the flight route to the $k$-th OI (FPR) takes into account not only the length of the section $D_{i}$, but also the UAV outfit (required number of UAVs for destruction (suppression) OI) $k$-th OI $N_{U A V . k}$ (11): 


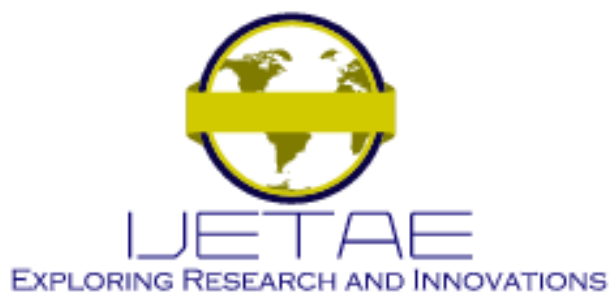

International Journal of Emerging Technology and Advanced Engineering

Website: www.ijetae.com (E-ISSN 2250-2459, Scopus Indexed, ISO 9001:2008 Certified Journal, Volume 11, Issue 09, September 2021)

$$
L_{i}=\frac{1}{D_{i} \cdot N_{U A V . k}}
$$

The increase in the level of pheromone $\Delta F_{i}^{\text {best }}$ will be defined as:

$$
\Delta F_{i}^{\text {best }}=\left\{\begin{array}{rr}
\frac{1}{L_{\text {best }} \cdot N_{U A V . k}}, \text { if the } i \text {-th route is the } \\
\text { best in iteration }
\end{array},\right.
$$

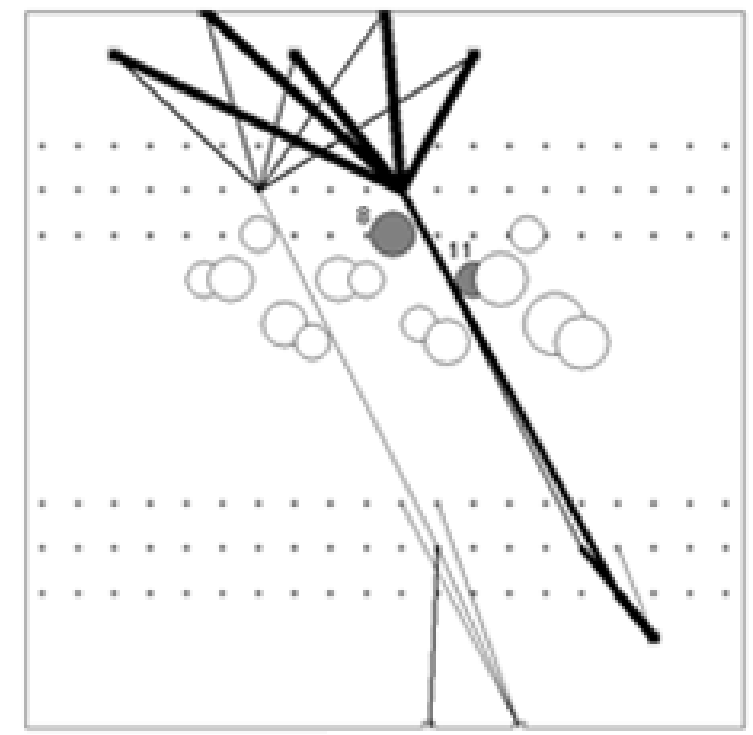

a)
Fig. 6 shows the results of calculations for the control example given in [29], but the availability of sections of the route and the increase in pheromone levels were calculated by (11) and (12).

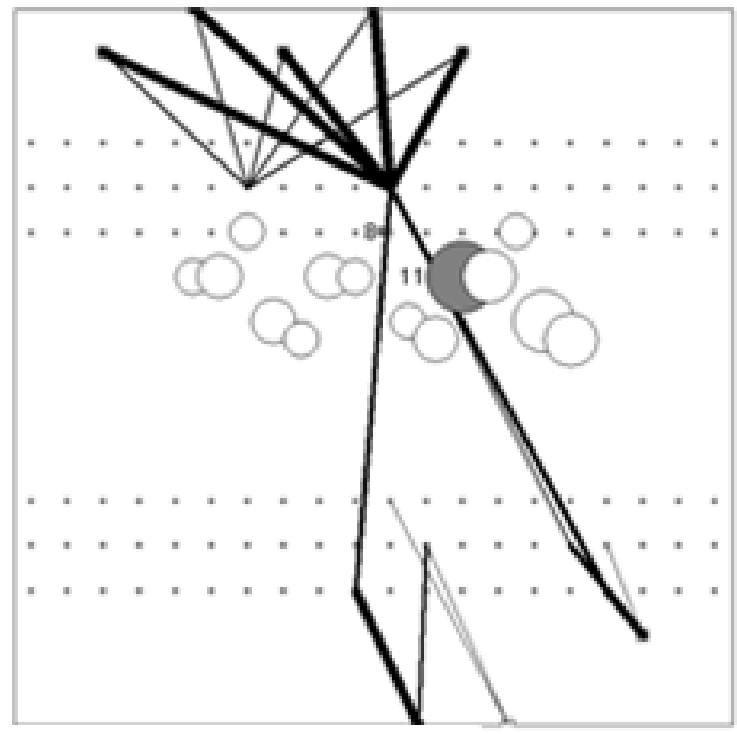

b) 


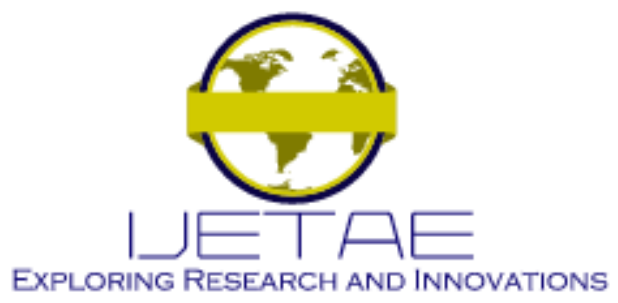

International Journal of Emerging Technology and Advanced Engineering

Website: www.ijetae.com (E-ISSN 2250-2459, Scopus Indexed, ISO 9001:2008 Certified Journal, Volume 11, Issue 09, September 2021)

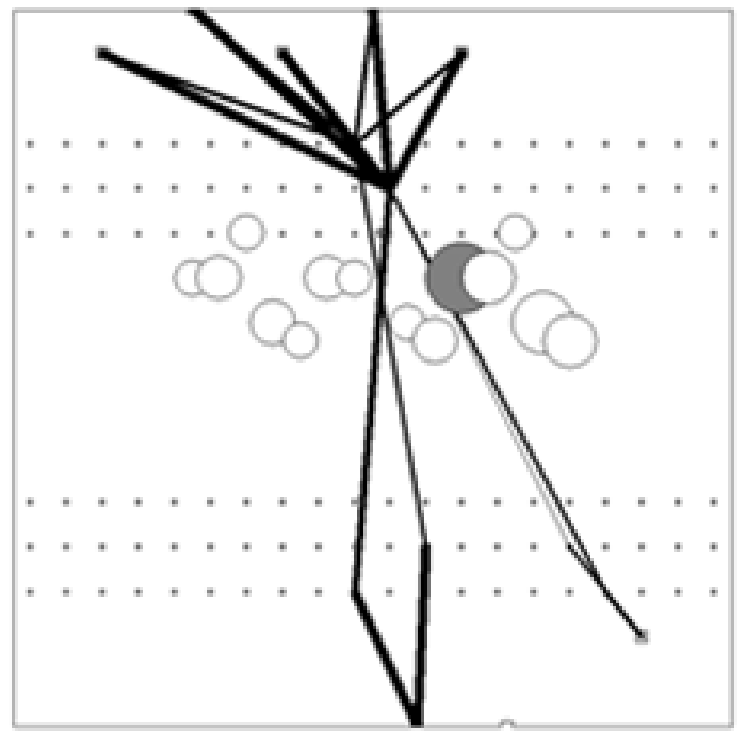

c)

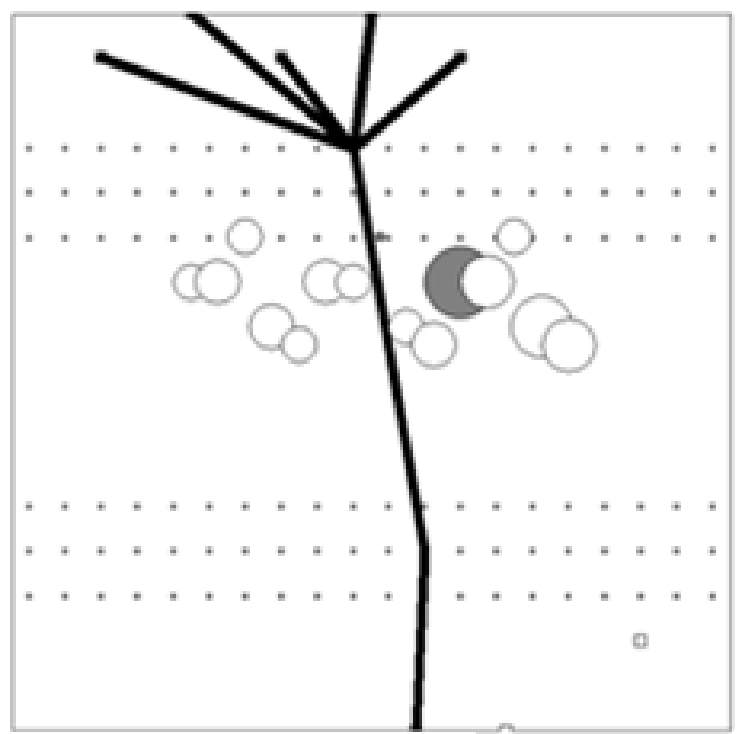

d)

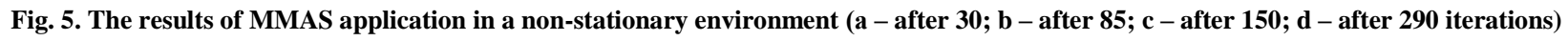

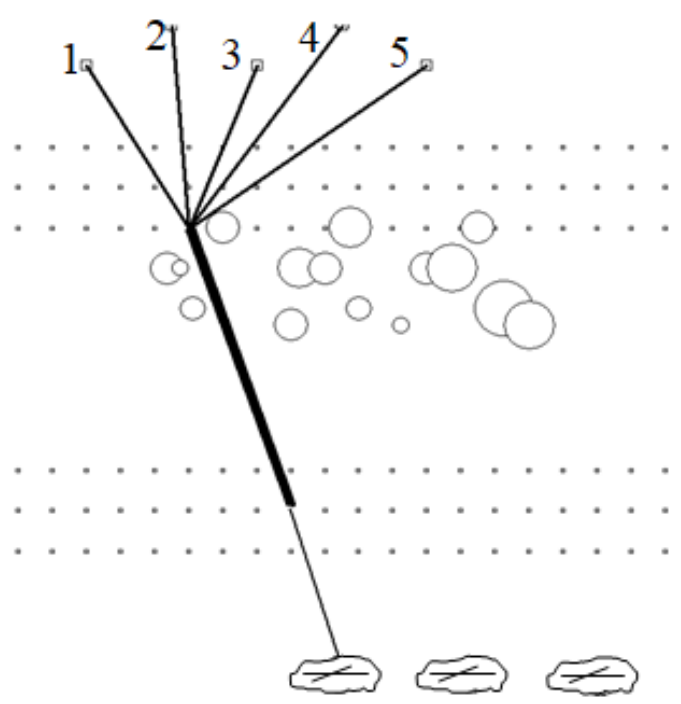

a) at $\mathrm{N}_{\mathrm{UAV} 1}=20, \mathrm{~N}_{\mathrm{UAV} 2}=4, \mathrm{~N}_{\mathrm{UAV} 3}=4, \mathrm{~N}_{\mathrm{UAV} 4}=4, \mathrm{~N}_{\mathrm{UAV}} 5=4$

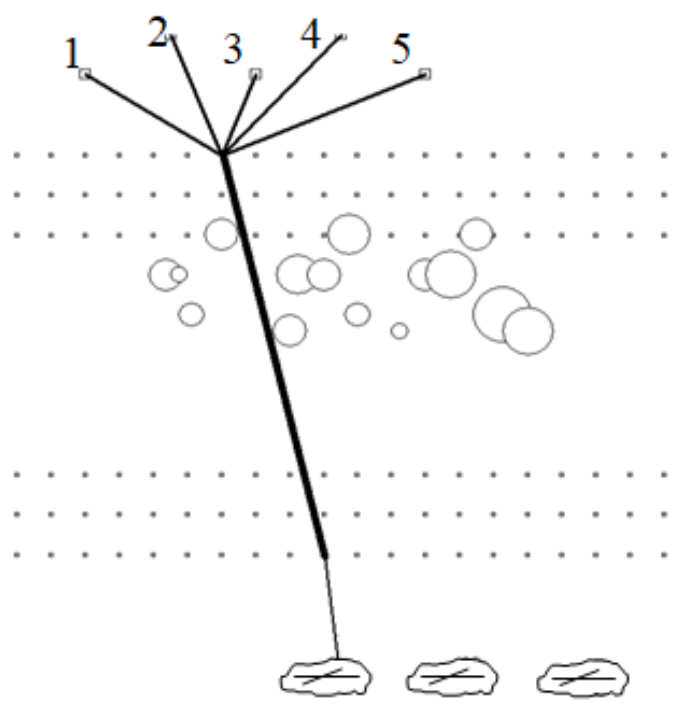

b) at $\mathrm{N}_{\mathrm{UAV} 1}=4, \mathrm{~N}_{\mathrm{UAV} 2}=20, \mathrm{~N}_{\mathrm{UAV} 3}=4, \mathrm{~N}_{\mathrm{UAV} 4}=4, \mathrm{~N}_{\mathrm{UAV}}=4$ 


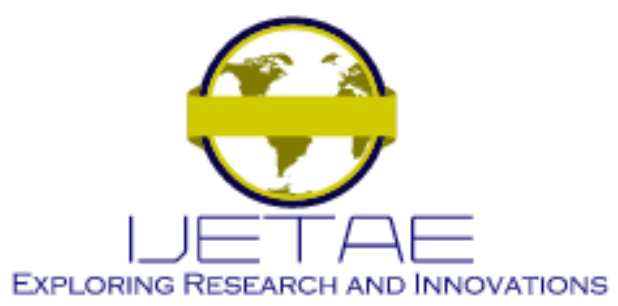

International Journal of Emerging Technology and Advanced Engineering Website: www.ijetae.com (E-ISSN 2250-2459, Scopus Indexed, ISO 9001:2008 Certified Journal, Volume 11, Issue 09, September 2021)

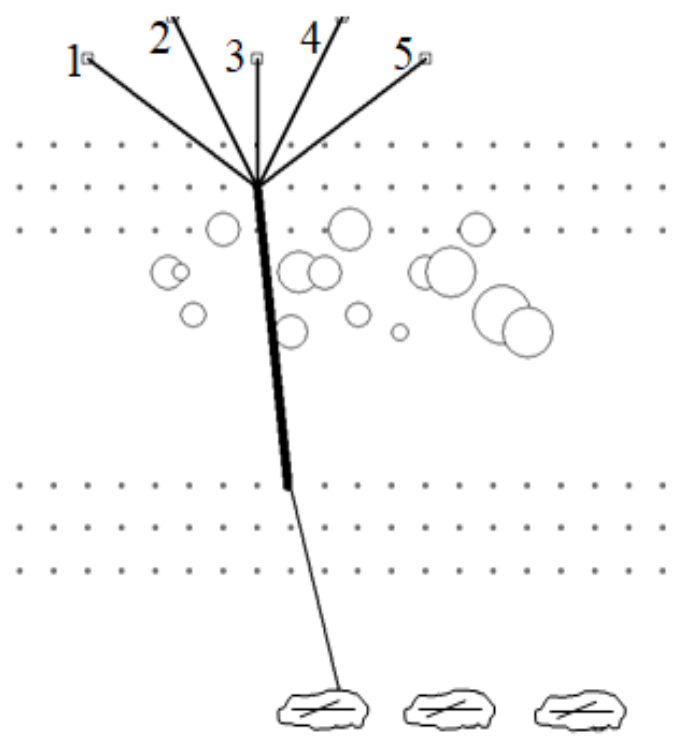

c) at $\mathrm{N}_{\mathrm{UAV} 1}=4, \mathrm{~N}_{\mathrm{UAV} 2}=4, \mathrm{~N}_{\mathrm{UAV} 3}=20, \mathrm{~N}_{\mathrm{UAV} 4}=4, \mathrm{~N}_{\mathrm{UAV} 5}=4$

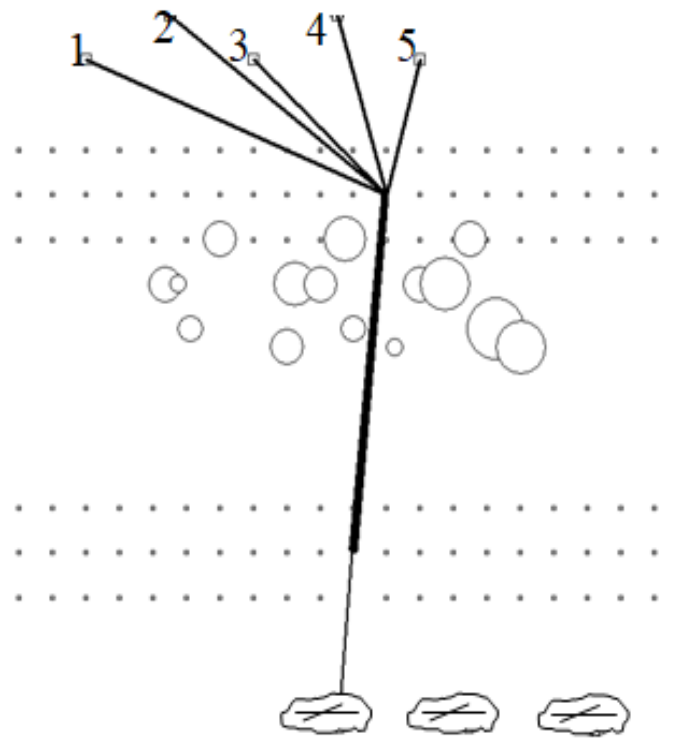

d) at $\mathrm{N}_{\mathrm{UAV} 1}=4, \mathrm{~N}_{\mathrm{UAV} 2}=4, \mathrm{~N}_{\mathrm{UAV} 3}=4, \mathrm{~N}_{\mathrm{UAV} 4}=4, \mathrm{~N}_{\mathrm{UAV}} 5=20$

Fig. 6. The results of the MMAS, taking into account the impact of the UAV outfit

In all cases, the algorithm determined the flight routes of the UAV in such a way as to ensure the shortest route length from SPR to those OI for which the largest UAV outfits are intended.

The reliability of the obtained results has been checked by comparing them with the results obtained by the method of complete search.

\section{CONCLUSIONS}

The paper presents the results of research on the use of MMAS to simultaneously determine the flight routes of several groups of UAVs from different airfields to different objects of impact and breakthrough of the air defense system, taking into account the impact of UAVs required to destroy an object with a given probability. Within the area of space in which the "no-fly zone" are located, the routes of different UAVs coincided. Also, studies on the performance of the algorithm in a non-stationary environment. To do this, after several steps of the iterative process, when agents gradually increased the level of the pheromone on several suboptimal routes, the size and location of the "restricted areas" changed. The MMAS quickly adapted to the changes and built a new solution, optimal in the new conditions.
In the future, the work will be aimed at the implementation of three-dimensional determination of UAV flight routes, taking into account the size of the turning points of the route. The study will also take into account the real contours of the "no-fly zone" and the terrain.

\section{REFERENCES}

[1] Retrieved from https://www.deltaquad.com/vtol-dronesfor/agriculture/?gclid=EAIaIQobChMI_IeD9qe98gIVlpKyCh3FoAL REAAYBCAAEgLqAfD_BwE.

[2] Retrieved from https://www.velosuav.com/v3newpic/?gclid= EAIaIQobChMItM_qzqi98gIVeAWiAx0kWQnjEAAYASAAEgIl0 vD_BwE.

[3] Retrieved from https://digitalaerolus.com/drones-in-the-oil-and-gasindustry.

[4] Retrieved from https://www.mosaicmill.com/forestry/UAV inventory.html?gclid=EAIaIQobChMI8tr8k6m98gIVsQZ7Ch1RiQr PEAAYASAAEgLFQvD_BwE.

[5] Armenia Azerbaijan: Reports of fresh shelling dent ceasefire hopes. (2020). Available from: https://www.bbc.com/news/world-europe54488386.

[6] Civil War in Syria. (2020). Available from: https://www.cfr.org/global-conflict-tracker/conflict/civil-war-syria. 


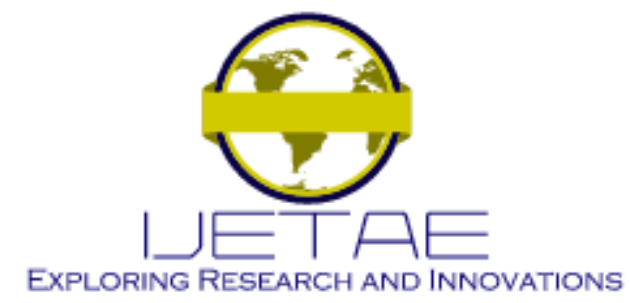

International Journal of Emerging Technology and Advanced Engineering

Website: www.ijetae.com (E-ISSN 2250-2459, Scopus Indexed, ISO 9001:2008 Certified Journal, Volume 11, Issue 09, September 2021)

[7] Khudov, H., Yarosh, S., Droban, O., Lavrut, O., Hulak, Y., Porokhnia, I., Yarovyi, S., Rogulia, A., Yuzova, I., \& Khudov, R. (2021). Development of a direct penetrating signal compensator in a distributed reception channel of a surveillance radar. EasternEuropean Journal of Enterprise Technologies, 2(9) (110), 16-26. https://doi.org/10.15587/1729-4061.2021.228133.

[8] Barabash O., Dakhno N., Shevchenko H., Majsak T. (2017). Dynamic Models of Decision Support Systems for Controlling UAV by Two-Step Variational-Gradient Method, Proceedings of 2017 IEEE 4th International Conference "Actual Problems of Unmanned Aerial Vehicles Developments (APUAVD)", October 17-19, 2017, Kyiv, Ukraine. 108-111. DOI:https://doi.org/10.1109/APUAVD.2017.8308787.

[9] Khudov, H., Ruban, I., Lysytsya, V., Kuzyk, P., Symkanych, O., and Khudov, R. The Method for Determination of Bone Marrow Cells in Photographic Images, International Journal of Emerging Trends in Engineering Research, Vol. 8. № 9, 2020, pp. 5681-5687. DOI: https://doi.org/10.30534/ijatcse/2020/131892020.

[10] Ruban, I., Khudov, H., Lishchenko, V., Pukhovyi, O., Popov, S., Kolos, R., Kravets, T., Shamrai, N., Solomonenko, Y., \& Yuzova, I. (2020). Assessing the detection zones of radar stations with the additional use of radiation from external sources. Eastern-European Journal of Enterprise Technologies, 6/9 (108), 6-17. https://doi.org/10.15587/1729-4061.2020.216118.

[11] Ergezer, $\mathrm{H}$ and Leblebicioglu, K. Path planning for UAVs for maximum information collection using evolutionary computation. IEEE Trans Aerosp Electr Syst 2013; 49(1): 502-520.

[12] Ergezer, $\mathrm{H}$ and Leblebicioglu, K. 3D path planning for UAVs for maximum information collection. J Intell Robot Syst 2014; 73: 737762 .

[13] Nguyen, H., V., Rezatofighi, H., Vo, B-N, et al. Online UAV path planning for joint detection and tracking of multiple radio-tagged objects. IEEE Trans Signal Process 2019; 67(20): 5365-5379.

[14] Semiz, F and Polat, F. Solving the area coverage problem with UAVs: a vehicle routing with time windows variation. Robot Autonom Syst 2020; 126: 103435.

[15] Gonz'alez-Sieira, A, Cores, D, Mucientes, M, et al. Autonomous navigation for UAVs managing motion and sensing uncertainty. Robot Autonom Syst 2020; 126: 103455.

[16] Patle, B. K., Pandey, A., Jagadeesh, A., et al. Path planning in uncertain environment by using firefly algorithm. Def Technol 2018; 14: 691-701.

[17] Abad, E. C., Alonso, J. M., Garcia, M. J. G., et al. Methodology for the navigation optimization of a terrain-adaptive unmanned ground vehicle. Int J Adv Robot Syst 2018; 15: 1729881417752726.

[18] Corral. E, Garcia. M. J. G., Castejon, C., et al. Dynamic modeling of the dissipative contact and friction forces of a passive biped-walking robot. Appl Sci 2020; 10: 2342.

[19] Afonso, R. J., Maximo, M. R., and Galvao, R. K. Task allocation and trajectory planning for multiple agents in the presence of obstacle and connectivity constraints with mixed-integer linear programming. Int J Robust Nonlin Control 2020; 30(14): 54645491.

[20] Zuo, Y, Tharmarasa, R., Jassemi-Zargani, R, et al. MILP formulation for aircraft path planning in persistent surveillance. IEEE Trans Aerosp Electr Syst 2020; 56(5): 3796-3811.
[21] Yang, Q. and Yoo, S. Optimal UAV path planning: sensing data acquisition over IoT sensor networks using multi-objective bioinspired algorithms. IEEE Access 2018; 6: 13671-13684.

[22] Oleksenko, O., Khudov, H., $\quad$ Petrenko, K., Horobets, Y., Kolianda, V., Kuchuk, N., Konstantinov, A., Kireienko, V., Serdiuk, O., Yuzova, I., Solomonenko, Y. (2021). The Development of the Method of Radar Observation System Construction of the Airspace on the Basis of Genetic Algorithm. International Journal of Emerging Technology and Advanced Engineering. 11, 8, 23-30. DOI: https://doi.org/10.46338/ijetae0821_04.

[23] Li, W., and Cassandras, C. G. (2006). Centralized and distributed cooperative receding horizon control of autonomous vehicle missions. Math Comput Modell; 43(9-10): 1208-1228.

[24] Wang, Y., Zhao, M., Yang, W., et al. (2020). Collision-free trajectory design for 2-d persistent monitoring using second-order agents. IEEE Trans Control Netw Syst., 7(2): 545-557.

[25] Belkadi, A., Abaunza, H., Ciarletta, L., et al. (2019). Design and implementation of distributed path planning algorithm for a fleet of UAVs. IEEE Trans Aerosp Electron Syst., 55: 2647-2657.

[26] Ergezer, H. and Leblebicioglu, K. (2021). Online path planning for unmanned aerial vehicles to maximize instantaneous information. International Journal of Advanced Robotic Systems. Available from: https://journals.sagepub.com/doi/pdf/10.1177/17298814211010379.

[27] LaValle, S. M. (2006). Planning algorithms. Cambridge: Cambridge University Press, 842 .

[28] V. Lishchenko, H. Khudov, B. Lisogorsky, O. Baranik, D. Holovniak, and O. Serdjuk (2020) The MIMO System on Based Existing Mechanical Rotation Radars with Wide Surveillance Area, in 2020 IEEE 40th International Conference on Electronics and Nanotechnology (ELNANO), 625-628. DOI: https://doi.org/10.1109/ELNANO.50318.2020.90887463.

[29] Khudov, H., Oleksenko, O., Kuchuk, N., Yaroshenko, Y., Ishchenko, O., Ikaiev, D., Kireienko, V. (2021). Determining the unmanned aerial vehicle optimal flight route based on the ant colony optimization. Turkish Online Journal of Qualitative Inquiry (TOJQI). 12, 6, 5173-5178.

[30] Ruban, I., and Khudov, H. (2020). Advances in Spatio-Temporal Segmentation of Visual Data, Chapter 2. Swarm Methods of Image Segmentation. Series Studies in Computational Intelligence (SCI). 876. - Publisher Springer, Cham, 53-99. DOI https://doi.org/10.1007/978-3-030-35480-0.

[31] Khudov, H., Ruban, I., Makoveichuk, O., Pevtsov, H., Khudov, V., Khizhnyak, I., Fryz, S., Podlipaiev, V., Polonskyi, Y., and Khudov, R. (2020). Development of methods for determining the contours of objects for a complex structured color image based on the ant colony optimization algorithm, Eureka: Physics and Engineering, (1), 34-47. DOI: https://doi.org/10.21303/24614262.2020.001108.

[32] Ruban, I., Khudov, H., Makoveichuk, O., Chomik, M., Khudov, V., Khizhnyak, I., Podlipaiev, V., Sheviakov, Y., Baranik, O., and Irkha, A. (2019). Construction of methods for determining the contours of objects on tonal aerospace images based on the ant algorithms, Eastern-European Journal of Enterprise Technologies, (5/9 (101)), 25-34. https://doi.org/10.15587/17294061.2019.177817. 


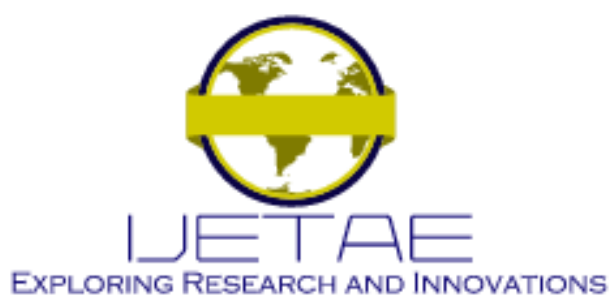

International Journal of Emerging Technology and Advanced Engineering

Website: www.ijetae.com (E-ISSN 2250-2459, Scopus Indexed, ISO 9001:2008 Certified Journal, Volume 11, Issue 09, September 2021)

[33] Dorigo, M., Maniezzo, V., Colorni, A. (1996). Ant System: Optimization by a colony of cooperating agents. IEEE Transactions on Systems, Man, and Cybernetics, (Part B, vol. 26, no. 1, pp. 29-41.
[34] Khudov, H., Lishchenko, V., Irkha, A., and Serdjuk, O. (2019). The method of the high accuracy finding 2D coordinates in MIMO-radar based on existing surveillance radars, 2019 International Conference on Information and Telecommunication Technologies and Radio Electronics, UkrMiCo 2019, Odessa, Ukraine, 1-4, doi: 10.1109/UkrMiCo47782.2019.9165319. 